\title{
The assessment and management of pain in the demented and non-demented elderly patient
}

\author{
Daniel Ciampi de Andrade ${ }^{1,2}$, José Weber Vieira de Faria ${ }^{3}$, \\ Paulo Caramelli ${ }^{4}$, Luciana Alvarenga ${ }^{5}$, Ricardo Galhardoni ${ }^{1}$, \\ Silvia R.D. Siqueira ${ }^{1,5}$, Lin T. Yeng ${ }^{6}$, Manoel Jacobsen Teixeira'
}

\begin{abstract}
Persistent pain is a frequent health problem in the elderly. Its prevalence ranges from $45 \%$ to $80 \%$. Chronic diseases, such as depression, cardiovascular disease, cancer and osteoporosis have a higher prevalence in aged individuals and increase the risk of developing chronic pain. The presence of pain is known to be associated with sleep disorders in these patients, as well as functional impairment, decreased sociability and greater use of the health system, with consequent increase in costs. Alzheimer's disease patients seem to have a normal pain discriminative capacity and they may probably have weaker emotional and affective experience of pain when compared to other types of dementia. Many patients have language deficits and thus cannot properly describe its characteristics. In more advanced cases, it becomes even difficult to determine whether pain is present or not. Therefore, the evaluation of these patients should be performed in a systematic way. There are three ways to measure the presence of pain: by direct questioning (self-report), by direct behavioral observation and by interviews with caregivers or informants. In recent years, many pain scales and questionnaires have been published and validated specifically for the elderly population. Some are specific to patients with cognitive decline, allowing pain evaluation to be conducted in a structured and reproducible way. The next step is to determine the type of painful syndrome and discuss the bases of the pharmacological management, the use of multiple medications and the presence of comorbidities demand the use of smaller doses and impose contraindications against some drug classes. A multiprofessional approach is the rule in the management of these patients.
\end{abstract}

Key words: Alzheimer's disease, pain, chronic pain, elderly, cognitive impairment.

\section{Avaliação e manejo da dor em pacientes idosos com e sem demência}

\section{RESUMO}

Dor persistente é um problema de saúde frequente no idoso e sua prevalência varia de 45 a 80\%. Doenças crônicas, como depressão, distúrbios cardiovasculares, câncer e osteoporose tem alta prevalência em indivíduos idosos e aumentam o risco de desenvolver dor crônica. Nestes indivíduos, a presença de dor está associada a distúrbios do sono, prejuízo funcional, diminuição da sociabilidade e maior procura dos serviços de saúde, com o consequente aumento dos custos de saúde. Pacientes com Alzheimer têm

\section{Correspondence}

Daniel Ciampi de Andrade

Department of Neurology

University of São Paulo Medical School

Rua Dr. Ovídio Pires de Campos 01060-970 São Paulo SP - Brasil

E-mail: ciampi@usp.br

Received 28 April 2010

Received in final form 15 December 2010 Accepted 22 December 2010 uma capacidade discriminativa dolorosa normal e uma experiência afetiva e emocional da dor mais atenuada quando comparados com outros tipos de demência. Muitos pacientes

Department of Neurology, University of São Paulo Medical School, São Paulo SP, Brazil: 'Pain Center from the Department of Neurology, Faculdade de Medicina, University of São Paulo, São Paulo SP, Brazil; 'PPain Center, Instituto do Câncer do Estado de São Paulo, Octavio Frias de Oliveira, São Paulo SP, Brazil; ${ }^{3}$ Division of Neurological Surgery, Federal University of Uberlândia Medical School, Uberlândia MG, Brazil; ' ${ }^{4}$ Department of Internal Medicine, Faculty of Medicine, Federal University of Minas Gerais, Belo Horizonte MG, Brazil; ${ }^{5}$ Dentistry Division, University of São Paulo Medical School, São Paulo SP, Brazil; ${ }^{6}$ Physical Medicine Division, Instituto de Ortopedia e Traumatologia, Faculdade de Medicina, University of São Paulo, São Paulo SP, Brazil. 
têm déficits de linguagem e não podem descrever adequadamente as características de sua dor. Em casos avançados, torna-se difícil determinar se a dor está realmente presente ou não. Desta forma, a avaliação destes doentes deve ser realizada de forma sistemática. Há três formas de se avaliar a dor: questionários diretos, observação direta do comportamento ou entrevistas diretas com os cuidadores ou informantes. Nos últimos anos muitas escalas e questionários para dor foram publicados e validados especificamente para a população idosa. Alguns são específicos para pacientes com declínio cognitivo, permitindo que a evolução da dor possa ser conduzida de uma forma estruturada e reprodutível. O passo seguinte é se determinar o tipo de síndrome dolorosa e se discutir as bases do manejo farmacológico. O uso de múltiplas medicações e a presença de comorbidades exige o uso de pequenas doses e impõem contra-indicações para algumas classes de drogas. A abordagem multidisciplinar é a regra no seguimento a longo prazo destes doentes.

Palavras-chave: idoso, doença de Alzheimer, comprometimento cognitivo, dor crônica, avaliação da dor.

In 2000, the population of individuals aged over 60 years reached 600 million. Estimation suggests that by 2025 there will be 1.2 billion and in 2050, about 2 billion elderly people worldwide. Both in the developed and developing world citizens over 80 years-old constitute the group with the highest rate of population growth ${ }^{1}$.

Old age exposes individuals to different types of pain. In addition, many chronic degenerative diseases have a higher prevalence in this age group, which, in turn, increase the risk of developing chronic pain, such as depression, cardiovascular disease, cancer and osteoporosis $^{2}$. While the overall risk of developing chronic pain increases with age, this rule is not universal. There are some specific types of pain that tend to diminish over the years. Examples are migraine, low back pain and some types of visceral pain (ie. elders may present gastric ulcers or "silent" acute myocardial infarction) $)^{1,3}$.

Persistent pain is a frequent health problem in the elderly. Its prevalence ranges from $45 \%$ to $80 \%$. In these individuals, the presence of pain is known to be associated with depression, sleep disorders, functional impairment, decreased sociability and greater use of the health system, with consequent increase in costs ${ }^{4,5}$. Improved recognition and clinical management of these conditions could provide substantial improvement in quality of life for older people, as well as reductions in social-economical burdens related to chronic pain.

Alzheimer's disease (AD) affects nearly $5 \%$ of persons aged over 65 years, and this proportion increases up to one third of those aged 85 and over ${ }^{6}$. The negative impact of pain in $\mathrm{AD}$ includes different painful conditions associated with older age, such as osteoarthritis, cancer and trauma. Numerous studies show a higher prevalence of pain in adults with dementia ${ }^{1-6}$. Non-treated pain is associated with depression, sleep problems, cognitive decline and greater functional dependence. The occurrence of pain is twice as common in people over 60 years compared to younger individuals ${ }^{7}$.

The aim of this study is to review the knowledge available on the physiology of pain in the elder, its particularities, assessment and the basis for its treatment. We searched Pubmed, Scopus and Web of Science for articles published from 1966 to 2010 containing the following key words: dementia, cognitive impairment, cognitive decline, pain assessment and quantitative sensory test. Only double blind, randomized, controlled trials were included, as well as systematic reviews. The recommendations are based on the best evidence available and on the opinion of the panel of experts in cases of limited published data on a certain subject.

\section{Physiology of pain in the elderly}

Do elderly people perceive painful stimuli as younger people do? Do elderly patients with dementia perceive pain in a similar way as patients who do not suffer from dementia? Some researchers tried to address these questions. However, most studies have evaluated a small number of individuals, using very heterogeneous methods. In most reports, the model used to measure the effect of pain in elderly persons was experimental pain, in which a painful stimulus was delivered to certain regions of the body and the patient was asked to indicate the detection, pain and tolerance thresholds, usually by pressing a button with the contralateral hand.

Detection thresholds refer to the lowest stimulus intensity able to be noticed by an individual. Pain threshold refers to the least intense stimulus intensity capable of triggering a painful sensation. Tolerance threshold is defined as the least intense painful stimulus intensity capable of triggering a withdrawal response or a request by the individual to stop the stimulus. Recent studies suggest that elderly patients presented higher thermal and 
mechanical pain thresholds than younger people ${ }^{7,8}$. The effect of age on tolerance to pain is more controversial, but most studies suggest that pain tolerance decreases with age. Thus, despite some conflicting results, aging is associated with a higher pain threshold and, at the same time, to a lower tolerance to painful stimuli, as if there was a "flattening" of the interval between the onset of pain and the point where it becomes unbearable, which is also called "limen" in psychophysics ${ }^{7-9}$.

This interpretation is consistent with anatomical and functional findings, which showed lower function of thin fibers transmitting nociceptive information ( $\mathrm{C}$ and $\mathrm{A}-\partial$ fibers) in the elderly, and reduced action of endogenous opioid system, a main component of the descending modulatory control of pain ${ }^{10}$.

Studies specifically evaluating the threshold and pain tolerance in elderly subjects with and without dementia are scarce. In a recent study, two tests of experimental pain were employed in elderly subjects with and without AD: pain evoked by electrical stimulation as a model of phasic pain and pain by compression of the arm by a tourniquet as a model of tonic pain ${ }^{11}$. Pain detection thresholds did not change between demented and non-demented patients. However, tolerance threshold was significantly higher in demented than in non-demented elders. This finding suggests that the sensorydiscriminative aspect of pain would be intact in these patients, while the affective-emotional component would be compromised. This interpretation is supported by the fact that brain regions responsible for sensory-discriminative aspect of pain, such as the lateral thalamus and the primary and secondary sensory cortex are relatively preserved, from the pathological point of view, in AD. On the other hand, the prefrontal cortices and limbic system, both related to emotional and affective aspects of pain experience, are preferred targets of the degenerative changes in $\mathrm{AD}^{12,13}$. Also, in this study, an interesting correlation was found between the severity of cognitive impairment and the magnitude of the dissociation between the tolerance and pain thresholds. This suggests that in more advanced cases of the disease, where more intense degenerative changes are expected, the dissociation between these two aspects of pain would be even more pronounced.

This 'dissociation' model based on the degree of structural changes could explain the fact that patients with vascular dementia ( $\mathrm{VaD})$ usually have more pain complaints than patients with AD. This could be related to a greater involvement of structures from the medial pain system (e.g. anterior cingulated, medial thalamus, anterior insula) in $\mathrm{VaD}$ compared to $\mathrm{AD}$. In line with this theory, a very elegant study on non-demented elders found a correlation between the extent of vascular lesions in the subcortical white matter (mainly correlated to the dorsolateral prefrontal cortex) and a greater intensity of the affective component of pain in this population $^{14}$. These authors also suggested that lesions affecting the connections between the prefrontal cortex and other structures could lead to lesser effectiveness of descending pain modulatory systems, thus contributing to the appearance of pain in subjects with central nervous system lesions, irrespective if their nature are primarily degenerative, vascular or demyelinating.

\section{Evaluation of the elderly patient with pain scales and questionnaires}

Pain assessment is the cornerstone of pain treatment, since pain that is not detected cannot be treated. Despite the obviousness of this statement, it highlights the need to systematically and actively assessing the presence of pain in the elderly, and to start a treatment based on the main pain syndromes. The diagnosis of chronic pain in the cognitively impaired imposes major challenges. Many patients have language deficits and thus cannot properly describe its characteristics. In more advanced cases, it becomes even more difficult to determine whether pain is present or not. Therefore, the evaluation of these patients should be performed in a systematic way.

The first question we must answer is whether the patient experiences or not pain. There are three ways to measure the presence of pain: by direct questioning (self-report), by direct behavioral observation and by interviews with caregivers or informants. In recent years, many pain scales and questionnaires have been published and validated specifically for the elderly population. Some are specific to patients with cognitive decline, allowing pain evaluation to be conducted in a structured and reproducible way. Below we list the main questionnaires used for this purpose, grouped according to the type of pain assessment.

Self-report tools - Self-report is the gold standard for the diagnosis of pain. It can be performed directly during history taking in patients with the preserved ability to communicate. Most of these scales were validated and, in some instances, were even compared to each other ${ }^{15}$.

One should be particularly cautious when using the visual analogical scale (VAS), because with increasing age, a higher proportion of incomplete or non-interpretable answers are found. Up to $30 \%$ of elderly people without cognitive impairment have difficulty using this scale $^{16}$. In general, older people report that the VAS is harder to use than other types of pain intensity scales, such as verbal descriptions, for example. However, VAS still remains one of the most commonly used tool in the clinical setting due to its practicality and availability. One 
should just be alert for signs of difficulties in its use, and be ready to propose the use of other scales when it occurs.

Other self-report assessment tools include:

- Functional Pain Scale (FPS): Scale of four items (yes / no) each ranging from 1 (no pain) to 5 (maximum pain $)^{17}$.

- Verbal Descriptor Scale (VDS): Two items rated from 1 (mild pain) to 6 (worst pain possible) ${ }^{18}$.

- Present Pain Intensity (PPI): One item, ranging from 1 (no pain) to 6 (excruciating pain). There is a "now" and "last week" version" ${ }^{19}$.

- Global Pain Assessment (GPA): One item with five levels (from "no pain" to "terrible"). There is a "now" and "last week" version" ${ }^{20}$.

Direct observation tools - In the United States of America, more than 50\% of nursing home residents have cognitive decline or dementia ${ }^{13}$. Studies in this population suggest that some patients with moderate or severe dementia can reliably report the presence of pain when asked ${ }^{16}$. However, spontaneous recall and integration of painful experiences are less reliable. Similarly, the number of complaints of pain expressed in a clear way tends to decrease over the course of dementia, while non-verbal expressions and behavior changes become more frequent. In these cases, social withdrawal, aggression, psychomotor agitation or mood swings may be a manifestation of the presence of pain.

The patient's behavior should be taken into account in the evaluation of elderly patients with pain. The following manifestations should be considered: [1] Facial expressions: sadness, grimacing, wrinkling of the forehead, scared faces, eyes closed or strongly shut, rapid blinks. [2] Verbalizations and non-verbal sounds: sighs, yawns, groans, wheezing, asking for help. [3] Body movements: rigid, tense body posture, defending an area of the body, shaking a body region. [4] Changes in interpersonal relationships: aggression, fighting, resistance to care, reduced social interactions, social withdrawal, verbal abuse, denying to eat, changes in appetite, increases sleep periods, increased wandering and interruption of previously established routines. [5] Mental status changes: crying, tears, irritability, increased confusion.

As can be seen, most of these items are extremely nonspecific and may be present, for example, in situations of general discomfort or dyspnea. However, this non-specificity underlines the fact that the expression of pain in elders may be heterogeneous. Its assessment should be actively and systematically looked for by the health care professional, who should not expect to find classic manifestations of pain in this population.

Many researchers have proposed the use of observational scales of behavior or pain signs, based on the premise that in cases of advanced dementia, direct ques- tioning might be insufficient or inaccurate ${ }^{16}$. There are some guidelines on how to perform the observation of pain behavior. Patients should be observed for a minimum of five minutes. Ideally, the patient should be asked to perform his usual movements, such as standing up, transferring with or without aid, sitting on the toilet and performing movements of the four limbs (actively when possible). Tools for assessing non-verbal pain are based on methods of observation of changes in behavioral and functional spheres, encompassing sleep, physical activity, mobility, body language and facial expression. Physiological measures like heart rate and blood pressure also provide valuable information, especially in cases of advanced dementia, but are less sensitive and specific. Some tools for direct observation of pain behavior are shown below:

- Pain Assessment in Advanced Dementia (PAINAD): Scale of five items, each with three levels ("no symptoms of pain" to "symptom that may indicate pain") ${ }^{21}$.

- Checklist of Nonverbal Pain Indicators (CNPI): Six items with responses from "yes / no" on the presence of pain ${ }^{22}$.

- Observational Pain Behavior Assessment Instrument (OPBAI): This scale for 17 items has seven levels, ranging from "none (a)" to "extreme" ${ }^{23}$.

- Doloplus-2: 10 items addressing somatic, psychomotor and psychosocial impact of pain. Each of the 10 items is rated on four levels, from 0 to 3, corresponding to increasing levels of pain. A score of 5 to 30 is considered indicative of pain ${ }^{24,25}$.

Caregiver reports - Since many patients with AD are institutionalized or have caregivers around most part of the day, the idea of performing an evaluation based on the impression of caregivers seems appealing. Some scales for caregivers report have been published and validated to systematize and make uniform ratings:

- Pain Assessment for the Dementing Elderly (PADE): It lists the scores made by the caregivers in a general score. It has 13 items with four levels: from "none" to "very much" 26.

- Pain Assessment Instrument in Non-Communicative Elderly (PAINE): 22 item scale, each with seven frequency levels: ranging from "never" to "every hour" 21.

Combined scales - Some scales use more than one type of pain assessment, providing, for example, self-report and behavioral observation scores in the same tool ${ }^{27}$ :

- Resident Assessment Instrument-Home Care (RAI-HC): A complete tool which assesses sociodemographic information, physical and cognitive status, physical condition and emotional health, formal and informal care (family), use of prescribed, and non-prescribed medications in a standardized way ${ }^{28}$. The scale includes the presence of pain, its frequency and intensity, as reported by patients (self-report) and by caregivers for the 
previous three days. In a recent study using this scale, almost half of the individuals in long-term institutions experienced daily pain and one out of five was not receiving pain relief ${ }^{4}$. The prescription of analgesics was lower in patients with cognitive decline and in those with communication difficulties. This tool was validated in a very large population consisting of 2779 elderly patients.

- McGill Pain Questionnaire: Combined scale for the elderly, which takes into account sensory, affective and evaluative aspects of pain. It briefly assesses the sensory and affective aspects of chronic pain and has been validated for this age group ${ }^{19,29}$.

Many studies have shown that observational scales tend to underestimate the subjective experience of pain $^{30,31}$. This is particularly true in cases of dementia. Expressions of pain tend to decrease with cognitive decline $^{32}$. In order to prevent pain under-assessment and under-treatment, as well as their negative consequences, greater emphasis should be given to regular and pre-programmed assessment. Thus, the use of validated tools for pain assessment in centers for the elderly should be promoted and disseminated, with attention to regular assessments and the nuances between the different types of scales and questionnaires ${ }^{33}$.

\section{Determining the type of painful syndrome}

Chronic pain can be divided into three different types of pain syndromes: pain due to excess of nociceptive inputs, neuropathic pain and dysfunctional pain. This division is simplistic, but is useful in organizing pain groups based on their response to certain types of treatment and prognosis.

Pain due to excess of nociceptive inputs is the most frequent pain syndrome in the general population. It includes all instances where there is an over-activation of intact somato-sensory pain pathways. Bone fractures, bruises, myofascial pain syndromes, some types of cervicogenic headaches, and osteoarthritis, are all examples of conditions where there is tissue damage and, consequently, a chemical hyperactivation of the ascending tracts transmitting the painful information. Up to $65 \%$ of new patients referred to pain centers may have this pain syndrome ${ }^{34,35}$.

Neuropathic pain is a painful condition caused by a direct injury or dysfunction of the somato-sensory pathways, at any level. It includes peripheral neuropathies, lesions of nerve trunks or plexuses, spinal cord or the cerebral cortex. Neuropathic pain usually manifests itself by spontaneous or paroxysmal pains, with burning or electric shock characteristics. The occurrence of some sensory phenomena is typical, including allodynia and hyperalgesia. Allodynia is defined as pain evoked by a stimulus that normally does cause pain. The classic ex- ample is the presence of pain when cotton is applied on the skin or slight contact with cold objects is made. Hyperalgesia is characterized by an increased response to pain after a certain stimulus, to a higher level than normally expected. For example, a patient who might report pain intensity of 2/10 on the VAS when his forearm is pricked by a needle on the healthy side would report pain intensity of $6 / 10$ when the needle is applied to the skin innervated by an injured nerve trunk. Thus, the presence of well-documented injuries to somato-sensory pathways (e.g. nerve injury after a fracture) associated with burning or electric shock-like pain, specially in the presence of allodynia or hyperalgesia will confirm the diagnosis of neuropathic pain, which has direct impact on the therapeutic approach, as we shall see forward.

In recent years, some questionnaires have been proposed and validated for screening patients with neuropathic pain. The "Douleur Neuropathique 4" (DN-4) is a validated and easy to apply questionnaire ${ }^{36}$. It consists of seven questions concerning the qualities of the pain, that must be answered yes or no, and three additional items that are part of a simplified sensory examination over the painful area. The answer "yes" to four or more questions is associated with $83 \%$ of sensitivity of and $90 \%$ of specificity. This questionnaire has been recently validated to the Portuguese language for clinical use in Brazil ${ }^{37}$. This is currently the only validated tool to assess neuropathic pain in the Portuguese language.

The presence of neuropathic pain is important to be determined in clinical settings, since it requires a specific treatment and does not respond well to common analgesics such as anti-inflammatory drugs. Unfortunately, to date there are no specific scales to assess neuropathic pain in the elderly population. In clinical practice, it is possible to use general tools such as the DN-4 in patients with early or moderate $\mathrm{AD}$, who can still respond to simple yes-no questions satisfactorily. Pain in patients with advanced $\mathrm{AD}$ may present a challenge to classify in specific syndromes.

The dysfunctional pain syndromes constitute a somewhat controversial group, since these patients present with no anatomic lesions related to their pain syndrome, and yet may have intense pain with a negative impact in quality of life. These are the cases of fibromyalgia, irritable bowel syndrome and some types of headache ${ }^{38}$. In clinical settings, many patients may present with more than one painful syndrome, which is called combined or mixed pain, representing a further difficulty when assessing demented patients ${ }^{39}$. A classic example is cancer pain. Patients with cancer are subject to different causes of pain (direct invasion of the tumor, side effects of treatment, involvement of the nerves, myofascial pain syndromes). In cases where the syndrome is combined and 
complex, the challenge is to identify the different types of pain that are present and to properly handle them, in a rational and coordinated manner. Assessment tools to differentiate these different components of mixed pain in the elderly are not available and the clinician is left with her/his clinical judgment and the tools designed for nondemented elderly patients.

\section{Basis of the pharmacological management of pain in the elderly}

The occurrence of adverse events in the elderly is more frequent than in younger individuals, and it may sometimes emerge despite the use of lower doses of medications. Possible causes for this higher sensitivity in the elderly population include age-related changes in metabolism and elimination of several drugs, in addition to the higher prevalence of polypharmacy, resulting from the increased incidence of concomitant diseases. This last point is a major challenge. The elderly have a higher number of comorbidities, which in turn imposes a greater number of contraindications against pain drugs.

There are specific recommendations for this age group published by Geriatric societies, such as the American Geriatrics Society. These guidelines are based on WHO recommendations, which in 1990 published recommendations for the rational use of analgesics based on an "analgesic scale" ${ }^{1}$. According to the WHO analgesic scale, patients with mild pain should receive nonsteroidal anti-inflammatory drugs. In cases of gastrointestinal, cardiac or renal contraindications, preference for drugs with lower anti-inflammatory effects, such as paracetamol (or dipyrone in Brazil) is suggested. In cases of moderate pain, it is advisable to use a combination of a nonsteroidal anti-inflammatory drug (NSAID) and a weak opioid such as codeine and propoxyphene, or a mixed opioid such as tramadol. Severe pain is treated with anti-inflammatory drugs associated with strong opioids such as morphine, hydromorphone, methadone, oxycodone and fentanyl, among others. Each of these medications has a different route of administration, which may be preferred in specific situations, for example, sublingual, transdermal, or rectal.

There are several publications testing the use of these recommendations in elderly patients and a few that were specifically tested in patients with dementia. In one of these studies, a treatment protocol based on AGS/WHO recommendations was used in institutionalized demented elderly ${ }^{40}$. Pain intensity assessments were systematically carried out every two weeks and patients were treated according to the analgesic ladder. For patients in whom pain was still present, a higher level of the ladder was started. When pain was present, assessment occurred every two days, and treatment side-effects were assessed. Among participants, who had an average score of 6 in the Mini-Mental State Examination (ie. severe dementia) half were considered as having pain. Among the various instruments used, the assessment of global pain scale was more sensitive for detecting pain, while the scale of visual descriptors was the most effective way to monitor the response to drug treatment. In this study, all patients who received the analgesic protocol achieved adequate pain control, which demonstrates the validity of a structured approach to diagnosis, evaluation and treatment of pain in patients with dementia.

Despite the great value of systematic approaches such as the WHO analgesic scale, there are some situations where it may not appropriate. For example, in cases of neuropathic pain, the pharmacologic approach is based primarily on the use of antidepressants and antiepileptic drugs. Hence, this structured approach may not be suitable to treat all patients irrespective of their pain syndrome, and a more tailored drug therapy may be necessary in specific situations. Regardless of the pharmacological approach chosen, side-effects should be evaluated in a systematic and regular basis, ideally, by members of care teams, using questionnaires and assessment tools. Some side-effects such as constipation, diarrhea, excessive sedation, mental state alterations, falls, worsening of walk and nausea are associated with polypharmacy and should be monitored.

\section{Non-pharmacological interventions}

Psychological treatment - There are few studies evaluating the benefit of psychological approaches in elderly patients with pain and fewer are those assessing the benefit in individuals with dementia. However, some publications have reported benefits from cognitive behavioral therapy, biofeedback and behavioral therapy in the elderly ${ }^{16}$. Patients with moderate or advanced dementia tend to benefit modestly from these interventions, although there are few studies in this specific population ${ }^{41}$.

Physical activity therapy - Elderly benefit from physical interventions such as transcutaneous electrical nerve stimulation, massage and local application of heat and cold. A recent study showed that a physical activity program was able to reduce aversion beliefs related to fear pain during physical activity, and had analgesic effects in elderly patients with chronic low back pain $(\text { CLBP })^{42}$. CLBP has been a model for studying pain in the elderly and has contributed to better understanding of pain in this age group, opening up the perspective on the relationship between pain, cognitive and physical activity.

An elegant study showed that neuropsychological performance changes in the elderly suffering from CLBP and proposed that general cognitive changes would be 
Table. Summary and general recommendations for elderly patients with pain.

- Always ask about the presence of pain or ask the caregivers what is their impressions on the subject.

- Use validated instruments to investigate the occurrence of pain in elderly subjects, adapted to the cognitive level of each patient.

- Draw a basal behavioral profile for the elderly with cognitive decline, so it will be possible to monitor her/his behaviors and to detect changes related to the occurrence of pain.

- Evaluate the patient not only at rest, but also during physical and daily activities, such as change in recumbence, bathing and going to the bathroom.

- Point out to the patient, family and caregivers that pain is not part of normal aging.

- Evaluate psychological stress, quality of life and functional state of patients, their families and caretakers.

- Try to characterize the presence of different painful syndromes and start an adequate treatment for each of them.

- Combine pharmacological with non-pharmacological approaches whenever possible.

- Monitor the emergence of adverse events.

Involve caregivers and family members in the detection and combat on pain.

- Repeat evaluations regularly.

- Modify treatment plan to maximize functional status and to minimize side effects whenever possible.

Adapted from Gliese \&Melzack, $1999^{16}$.

the mediating factor in the relationship between pain and physical function ${ }^{43}$. This is a very interesting hypothesis and if it is further confirmed, it would bring important changes in the rehabilitation of these patients.

\section{Conclusions}

Pain in the elderly with or without dementia is not part of normal aging. The presence of pain should be assessed preferably through direct questioning to the patient and, if not possible, through interviews with caregivers or direct observation. AD patients seem to have a normal pain discriminative capacity and they may probably have weaker emotional and affective experience of pain when compared to other types of dementia. This fact only makes the diagnosis of pain in this group more difficult, but should not, by no means, hamper its assessment. Many scales exist to diagnose and follow-up the elders who experience pain and some are specific for those who have dementia. Pain treatment in the elderly may be similar to younger individuals. However, the use of multiple medications and the presence of comorbidities de- mand the use of smaller doses of medication and impose contra-indications against some drug classes (see Table for a summary of recommendations).

\section{REFERENCES}

1. The World Health Organization. The world is fast ageing - have we noticed? The time to plan and to act is now. Available at www.who.int/ageing/en/ Acessed 04,23,2009.

2. Soldato $M$, Liperoti $R$, Landi F, et al. Non malignant daily pain and risk of disability among older adults in home care in Europe. Pain 2007;129:304-310.

3. Gal LMP, Wajngarten M, Teixeira MJ, Azul LGS. Algias torácicas no idoso. Causas músculo-esqueléticas. Rev Bras Med Cardiol 1986;5:175-182.

4. Maxwell CJ, Dalby DM, Slater M, et al. The prevalence and management of current daily pain among older home care clients. Pain 2008;138:208-216.

5. Gomes JCPG, Teixeira MJ. Dor no idoso. Rev Bras Med (Rio de Janeiro) 2006; 63:554-563.

6. Herrera Jr. E, Caramelli P, Silveira ASB, Nitrini R. Epidemiological survey of dementia in a community-dwelling Brazilian population. Alz Dis Assoc Disord 2002;16:103-108.

7. Lautenbacher S, Strian F. Similarities in age differences in heat pain perception and thermal sensitivity. Funct Neurol 1991;6:129-135.

8. Chakour MC, Gibson SJ, Bradbeer M, Helme RD. The effect of age on A delta- and C-fibre thermal pain perception. Pain 1996;64:143-152.

9. Lasch H, Castell DO, Castell JA. Evidence for diminished visceral pain with aging: studies using graded intraesophageal balloon distension. Am J Physiol 1997;272:1-3.

10. Edwards RR, Fillingim RB, Ness TJ. Age-related differences in endogenous pain modulation: a comparison of diffuse noxious inhibitory controls in healthy older and younger adults. Pain 2003;101:155-165.

11. Benedetti F, Vighetti S, Ricco C, et al. Pain threshold and tolerance in Alzheimer's disease. Pain 1999;80:377-382.

12. Ciampi de Andrade $D$, Moiset $X$, Bouhassira D. Current therapy in pain. $1^{\text {st }}$. Ed. New York: Saunders, 2009;1:45-50.

13. Farrell MJ, Katz B, Helme RD. The impact of dementia on the pain experience. Pain 1996;67:7-15

14. Oosterman JM, van Harten B, Weinstein HC, Scheltens P, Scherder EJ. Pain intensity and pain affect in relation to white matter changes. Pain 2006; 125:74-81.

15. Gagliese L, Katz J. Age differences in postoperative pain are scale dependent: a comparison of quality of pain intensity and quality in younger and older surgical patients. Pain 2003:103:11-20.

16. Gagliese L, Melzack R. Pain in the elderly. In: Wall PD, Melzack R (Eds). Textbook of pain. 4a Ed. Edinburgh: Chirchill Livingstone, 1999:1169-1177.

17. Gloth FM 3rd, Scheve AA, Stober CV, Chow S, Prosser J.The Functional Pain Scale: reliability, validity, and responsiveness in an elderly population. J Am Med Dir Assoc 2001;2:110-114

18. Herr KA, Spratt K, Mobily PR, Richardson G. Pain intensity assessment in older adults: use of experimental pain to compare psychometric properties and usability of selected pain scales with younger adults. Clin J Pain 2004;20:207-219.

19. Melzack R. The McGill Pain Questionnaire: major properties and scoring methods. Pain 1975;1:277-299.

20. Cohen-Mansfield J. Pain assessment in noncommunicative elderly personsPAINE. Clin J Pain 2006;22:569-575.

21. Warden V, Hurley AC, Volicer L. Development and psychometric evaluation of the pain assessment in advanced dementia (PAINAD) scale. J Am Med Dir Assoc 2003;4:9-15.

22. Feldt KS. The checklist of nonverbal pain indicators (CNPI). Pain Manag Nurs 2000;1:13-21.

23. Horgas AL, Nichols AL, Schapson CA, Vietes K. Assessing pain in persons with dementia: relationships among the non-communicative patient's pain assessment instrument, self-report, and behavioral observations. Pain Manag Nurs 2007;8:77-85.

24. Wary B, Doloplus collectif. Doloplus-2, une échelle pour évaluer la douleur. Soins Gérontologie 1999;19:25-27.

25. Wary B, Serbouti S, Doloplus collectif. Validation d'une échelle d'évaluation comportementale de la douleur chez la personne âgés. Douleurs 2001;2:35-38.

26. Villanueva MR, Smith TL, Erickson JS, Lee AC, Singer CM. Pain assessment for the dementing elderly (PADE): reliability and validity of a new measure. J Am Med Dir Assoc 2003:4:1-8 
27. Cohen-Mansfield J, Parpura-Gill A. Practice style in the nursing home: dimensions for assessment and quality improvement. Int J Geriatr Psychiatry 2008;23:376-386.

28. Landi F, Tua E, Onder G, et al. Minimum data set for home care: a valid instrument to assess frail older people living in the community. Med Care 2000;38:1184-1190.

29. Pimenta CA, Teixeira MJ. Proposal to adapt the McGill Pain Questionnaire into Portuguese. Rev Escola Enfermagem USP 1996;30:473-483.

30. Pautex S, Herrmann F, Le Lous P, Fabjan M, Michel JP, Gold G. Feasibility and reliability of four pain self-assessment scales and correlation with an observational rating scale in hospitalized elderly demented patients. J Gerontol A Biol Sci Med Sci 2005;60:524-529.

31. Stolee P, Hillier LM, Esbaugh J, Bol N, McKellar L, Gauthier N. Instruments for the assessment of pain in older persons with cognitive impairment. J Am Geriatr Soc 2005;53:319-326.

32. Mäntyselkä P, Hartikainen S, Louhivuori-Laako K, Sulkava R. Effects of dementia on perceived daily pain in home-dwelling elderly people: a population-based study. Age Ageing 2004;33:496-499.

33. Scherder E, Oosterman J, Swaab D, et al. Recent developments in pain in dementia. BMJ 2005;330:461-464.

34. Teixeira MJ, Teixeira WGJ, Andrade DCA. Princípios gerais de tratamento da dor músculo-esquelética. Rev Med (FMUSP) 2001;80:170-178.

35. Teixeira MJ, Teixeira WGJ, Santos FPS, et al. Epidemiologia clínica da dor músculo-esquelética. Rev Med (FMUSP) 2001;80:1-21.

36. Bouhassira D, Attal N, Alchaar H, et al. Comparison of pain syndromes asso- ciated with nervous or somatic lesions and development of a new neuropathic pain diagnostic questionnaire (DN4). Pain 2005;114:29-36.

37. Santos JG, Brito JO, de Andrade DC, et al. Translation to Portuguese and validation of the douleur neuropathique 4 questionnaire. J Pain 2010;11: 484-490.

38. Nasri C, Teixeira MJ, Okada M, Formigoni G, Heir G, Siqueira JT. Burning mouth complaints: clinical characteristics of a Brazilian sample.Clinics 2007; 62:561-566.

39. Ferreira KA, Kimura M, Teixeira MJ, et al. Impact of cancer-related symptom synergisms on health-related quality of life and performance status. J Pain Symptom Manage 2008;35:604-616.

40. Cohen-Mansfield J, Lipson S. The utility of pain assessment for analgesic use in persons with dementia. Pain 2008;134:16-23.

41. Robinson L, Iliffe S, Brayne C, et al. Primary care and dementia: 2. Long-term care at home: psychosocial interventions, information provision, carer support and case management. Int J Geriatr Psychiatry 2010;25: 657-664.

42. Weiner DK, Perera S, Rudy TE, Glick RM, Shenoy S, Delitto A. Efficacy of percutaneous electrical nerve stimulation and therapeutic exercise for older adults with chronic low back pain: a randomized controlled trial. Pain 2008; 140:344-357.

43. Weiner DK, Rudy TE, Morrow L, Slaboda J, Lieber SJ. The relationship between pain, neuropsychological performance, and physical function in community-dwelling older adults with chronic low back pain. Pain Med $2006 ; 7: 60-70$ 